\title{
Primary and Secondary Renal Failure in a Total Community (Tecumseh, Michigan): Preponderance in the Elderly and Possible Antecedent Factors*
}

\author{
LAWRENCE V. PERLMAN, MD**, BRIAN W. KENNEDY, MD $†$ and NORMAN S. HAYNER, MD $\ddagger$
}

\section{The Center for Research in Diseases of the Heart, Circulation and Related Disorders, University of Michigan, Ann Arbor, Michigan}

\begin{abstract}
In 14 (8 men and 6 women) of the 8,641 original examinees in the Tecumseh Study, renal failure (RF) was found to have developed during an eight-year period. The proportion rose significantly with age. At the initial examination (one to eight years before the onset of RF), no subject subsequently uremic had a history of acute glomerulonephritis or chronic renal disease nor was frankly azotemic, although in 4 there was a suggestion of early disease. Six of the 12 subjects ( 50 per cent) over age 45 who later became uremic gave a history compatible with urinary-tract infection (UTI), compared with 380 ( 22 per cent) of the remaining 1,746 examinees in this age range. Conversely, in 6 of 386 persons (1.6 per cent) with a history of UTI, renal failure developed, in contrast to 6 of 1,372 persons ( 0.4 per cent) without such a history. Common disorders noted at the initial examination one to eight years before RF were congestive heart failure (9 cases), loss of hearing ( 7 cases), coronary heart disease ( 5 cases), hyperuricosemia (5 cases), and hyperglycemia ( 5 cases). This study shows that most persons in whom renal failure develops are elderly and have pre-existing vascular disease; in about a quarter of them, the findings at the time of the initial examination indicate early renal disease. Although these data point to a relationship between UTI and RF in some cases, in most patients with a history of UTI, renal failure does not develop.
\end{abstract}

The epidemiology of chronic renal failure and the prior characteristics of persons in whom it occurs are not well known (1). In recent studies of chronic renal disease, several authors examine the prevalence and sequelae of

* Work supported by Program Project Grant HE 09814 from the National Heart Institute, National Institutes of Health, U.S. Public Health Service.

This paper was presented in part at a Work-in-Progress Session on Epidemiologic Studies of Cardiovascular, Cerebrovascular, and Renal Diseases at the Second Annual Meeting of the Society for Epidemiologic Research, Chapel Hill, N.C., May 2, 1969.

** U.S.P.H.S. Heart Disease Control Officer during this investigation; then Assistant Professor, Department of Internal Medicine, Medical College of Wisconsin, Milwaukee, Wis.; now Associate Professor of Medicine bacteriuria, yet the manner and frequency by which this finding contributes to renal failure remain controversial (2-10). The relationship between acute glomerulonephritis and chronic renal disease also is not clear $(11,12)$. The

and Community Medicine, University of Pittsburgh School of Medicine, Pittsburgh, $\mathrm{Pa}$.

Correspondence to be addressed to: Lawrence V. Perlman, M.D., Associate Professor of Medicine and Community Medicine, University of Pittsburgh School of Medicine, 3601 Fifth Avenue, Pittsburgh, Pennsylvania 15261 .

$\dagger$ Instructor, Department of Medicine, Medical College of Wisconsin, Milwaukee, Wis.

$\ddagger$ Formerly Associate Professor, Department of Epidemiology, School of Public Health, University of Michigan, Ann Arbor, Mich. Present address: State Health Department, Lansing, Mich. 
majority of uremic patients give no history of either pre-existent glomerulonephritis (acute or chronic) or pyelonephritis, though recent pathologic and death certificate studies suggest that these represent the causes of most fatal renal disease (13-18).

The longitudinal study of health and disease in the total community of Tecumseh, Michigan, provides a unique opportunity to identify clinical conditions and physiologic variables which may represent precursors of renal failure. In 14 of the 8,641 persons examined at the start of this study, renal failure was found to have developed during an eight-year period (1959-1967). This report will describe the characteristics of these 14 patients at the time of their initial examinations and at the time of overt renal failure one to eight years later.

\section{METHODS}

During the initial (1959-1960) round of the Tecumseh Community Health Study, 8,641 persons of all ages ( 88 per cent of all residents) were interviewed and examined (19-21). Trained interviewers, in obtaining primary medical histories, asked each participant, "Have you ever had any trouble with your kidneys or bladder, such as infections or a kidney stone?" A parent, usually the mother, answered for children under 16 years of age. Positive answers were explored by the interviewer according to a prescribed schedule and amplified by the examing physician in order to identify urinary-tract infections, calculi, acute nephritis, and chronic renal disease. All men 20 years of age or older were asked about "prostate trouble" and nocturia; married women who reported pregnancies were asked about associated "kidney trouble." Responses, physical findings, and diagnoses were recorded and reviewed; the diagnoses were required to meet definite criteria established by the senior staff of the Tecumseh Community Health Study (Table 1). Systolic and diastolic blood pressure, serum cholesterol, serum uric acid, and blood glucose values (usually one hour after ingestion of 100 grams of glucose in water) were measured according to previously described techniques (21-25). Age and specific sex quintiles for these physiologic variables were calculated.

All death certificates for participants in the initial examination were reviewed through November 1967 (about eight years after the midpoint of the initial examination period); hospital records of those reported to have died with uremia or renal failure, chronic renal disease, glomerulonephritis, or pyelonephritis were studied systematically.

Twelve subjects were accepted on the basis of a serum urea nitrogen (SUN) level over 75 $\mathrm{mg} / 100 \mathrm{ml}$.; 2 others who had been certified as having died in a state of failure without a recorded SUN or serum creatinine value were accepted on the basis of a compatible clinical course supported in each case by autopsy findings demonstrating significant chronic renal disease.

From the time of the initial examination, serum specimens had been retained and promptly frozen. In January 1969, aliquots of these specimens for 13 of the 14 subjects with subsequent renal failure were thawed. Serum urea nitrogen and creatinine concentrations were determined by a modified MarshFingerhut-Miller method and a modified FolinWu method, respectively $(26,27)$.

\section{RESULTS}

Among the population examined, the distribution of those who experienced renal failure within eight years is shown in Table 2, by sex and age at the time of the initial examination. The 8 men and 6 women in whom renal failure developed satisfied the criteria stated previously. In 8 (1.7 per cent) of the 471 examinees 65 years of age or older, kidney failure developed within the eight-year period, compared with 6 ( 0.8 per cent) of 8,170 examinees under age 65. Thus, renal failure was not associated with sex, but a marked trend toward older age was apparent.

Clinical and laboratory findings from the initial examination were analyzed for each of the 14 subjects in whom renal failure developed in the period of observation. At initial examination, none of the subsequently uremic subjects of this study had given histories of either prior or present acute glomerulonephritis nor of chronic renal disease. Only 3 subjects were initially found to have albuminuria; of these, 1 had occasional casts and 1 had microscopic hematuria.

The distributions of urea nitrogen and creatinine determinations from sera obtained at the initial examination are shown in Table 3. None of the 13 specimens was found to be significantly abnormal, although 4 (including 


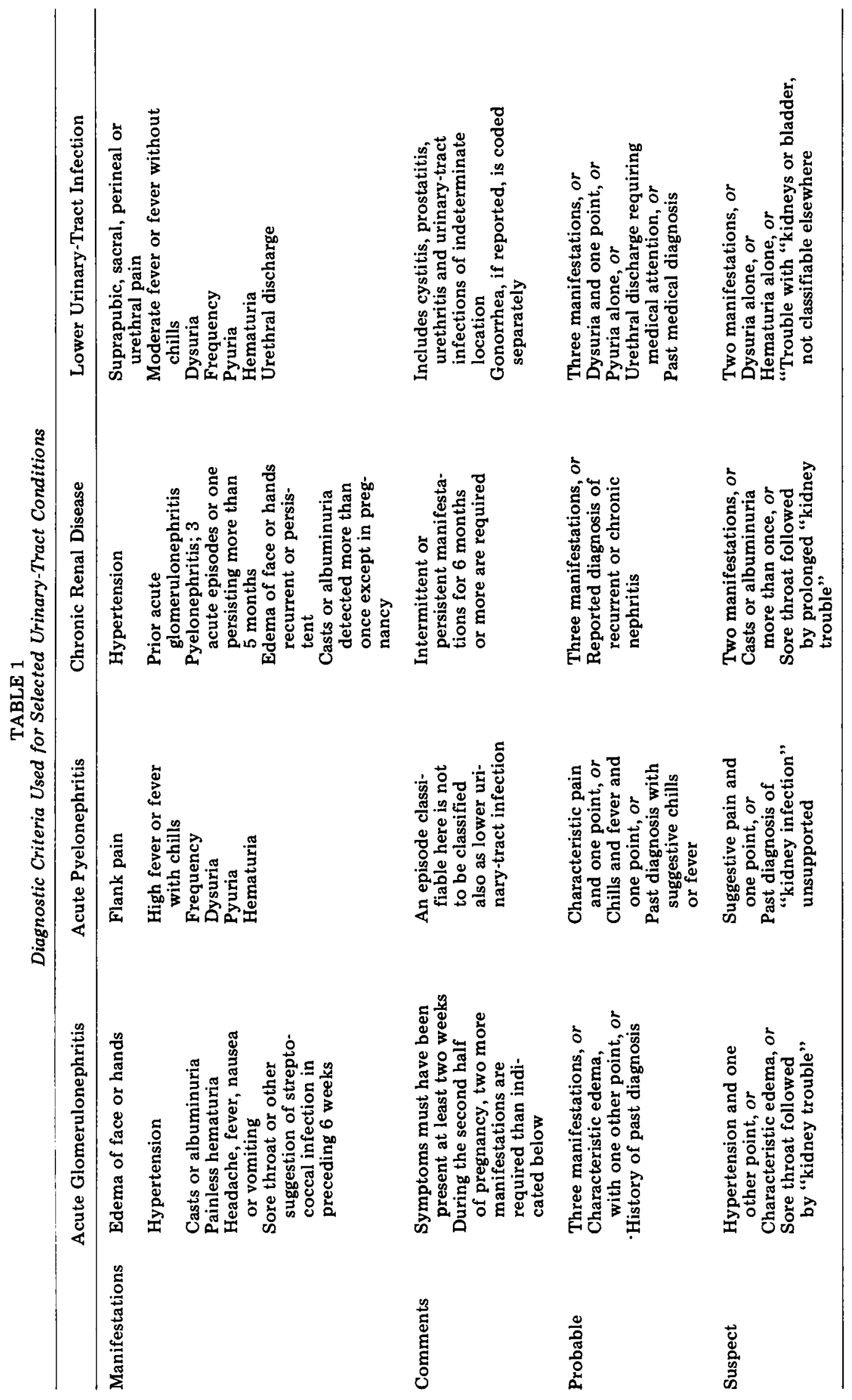


TABLE 2

Distribution of Subjects with Subsequent Renal Failure, by Sex and Age at Initial Examination (Tecumseh, Mich., 1959-1960)

\begin{tabular}{|c|c|c|c|c|c|c|c|c|c|}
\hline \multirow[b]{2}{*}{$\begin{array}{l}\text { Age Group } \\
\text { (yrs.) }\end{array}$} & \multicolumn{3}{|c|}{ Males } & \multicolumn{3}{|c|}{ Females } & \multicolumn{3}{|c|}{ Both sexes } \\
\hline & $\mathrm{N}_{\mathrm{E}}$ * & $\mathrm{N}_{\mathrm{RF}}{ }^{* *}$ & $\%$ & $\mathrm{~N}_{\mathrm{E}}$ & $\mathrm{N}_{\mathrm{RF}}$ & $\%$ & $\mathbf{N}_{\mathrm{E}}$ & $\mathrm{N}_{\mathrm{R} F}$ & $\%$ \\
\hline $0-19$ & 2,000 & 0 & 0.0 & 1,954 & 0 & 0.0 & 3,954 & 0 & 0.0 \\
\hline $20-44$ & 1,376 & 1 & 0.1 & 1,552 & 1 & 0.1 & 2,928 & 2 & 0.1 \\
\hline $45-64$ & 655 & 3 & 0.5 & 633 & 1 & 0.2 & 1,288 & 4 & 0.3 \\
\hline $65+$ & 207 & 4 & 1.9 & 264 & 4 & 1.5 & 471 & 8 & 1.7 \\
\hline All ages & 4,238 & 8 & 0.2 & 4,403 & 6 & 0.1 & 8,641 & 14 & 0.2 \\
\hline
\end{tabular}

$* \mathrm{~N}_{\mathrm{E}}=$ number examined.

$* * \mathrm{~N}_{\mathrm{RF}}=$ number with renal failure in the subsequent eight years.

TABLE 3

Distributions of Urea Nitrogen and Creatinine in Initial Serum Specimens from Subsequently Uremic Subjects (Tecumseh, Mich., 1959-1960)

\begin{tabular}{lcccc}
\hline \multicolumn{2}{c}{ Serum Urea Nitrogen } & & \multicolumn{2}{c}{ Serum Creatinine } \\
\cline { 1 - 2 } $\mathrm{mg} / 100 \mathrm{ml}$ & Number & & $\mathrm{mg} / 100 \mathrm{ml}$ & Number \\
\cline { 1 - 2 } $10-20$ & 6 & & $0.5-1.0$ & 6 \\
$21-30$ & 5 & & $1.1-1.5$ & 4 \\
$31-40$ & 2 & & $1.6-2.0$ & 3 \\
$40+$ & 0 & & $2.1+$ & 0 \\
no serum & 1 & & no serum & $\frac{1}{14}$ \\
\hline
\end{tabular}

those from the 3 subjects with albuminuria) were moderately elevated in one measure or both; 3 serum creatinine values fell between 1.5 and $2.0 \mathrm{mg} / 100 \mathrm{ml}$, and $2 \mathrm{SUN}$ values were in the $31.40 \mathrm{mg} / 100 \mathrm{ml}$ range. (Normal values for serum creatinine are less than $1.2 \mathrm{mg} / 100$ $\mathrm{ml}$, and for SUN less than $20 \mathrm{mg} / 100 \mathrm{ml}$.)

The presence or absence of an obtainable history of urinary-tract infection (UTI) is shown in Table 4 for subjects with or without subsequent renal failure. This comparison is confined to persons aged 45 or older at the time of the original examination in order to limit the bias introduced by age on both factors. A positive history of UTI was obtained from 6 (50 per cent) of the 12 subsequently uremic subjects in this age group; 380 (22 per cent of 1,746 persons in this age range) did not show renal failure but gave a history of UTI. Conversely, in 6 of a total of 386 persons (1.6 per cent) over age 45 with a history of UTI, renal failure developed, as compared to 6 of 1,372 ( 0.4 per cent) who did not have such a history. Although these numbers are considered too small for tests of statistical significance, there is a trend suggesting a relationship. Neither of the 2 subjects under age 45 gave a history of UTI.
Several other disorders possibly related to renal disease were observed at the time of the initial examination in the 14 persons with subsequent uremia. Seven patients had hearing loss, $\mathbf{5}$ had coronary heart disease (electrocardiographic evidence of myocardial infarction or a history of probable angina pectoris), 9 were or had been in a state of congestive heart failure, 1 had symptoms of prostatism, and 1 had diabetes mellitus. In comparison, for this age-sex distribution, 3.8 persons would be expected to have hearing loss, 2.0 to have coronary heart disease, and only 1.0 to have past or present congestive failure according to the 1959-1960 total study experience (20-28).

At the initial examination, evidence of coronary heart disease was found in 5 of the subjects who later became uremic. For this reason, selected physiologic measures which frequently have been implicated as risk factors in the latter disease were studied-blood glucose, systolic and diastolic blood pressure, serum cholesterol, and serum uric acid. One or more of these variables measured at the start of the observation period was in the highest age-and-sex-specific quintile in all 5 coronarydisease subjects and in 5 others of the 14 subjects. Observed and expected frequencies of each measurement found to be in the highest quintile (adjusted for age and sex) are presented in Table 5 for the 14 subjects in whom renal failure developed. The frequency of a blood glucose value in the top quintile was no higher than that expected by chance alone. Five of the 12 subjects with elevated serum uric acid levels were in the uppermost quintile; only 1 of these 5 had gouty arthritis at or before the initial examination. The 2 subjects with SUN concentrations in the range of $31-40$ $\mathrm{mg} / 100 \mathrm{ml}$, all had serum uric acid values in the highest quintile. 
Hospital records provided the data on urinalysis, maximal SUN concentration, and major clinical findings in the patients after overt renal failure had developed. All but 1 of the 13 subjects for whom a urinalysis was recorded after the onset of renal failure had one or more abnormal urinary constituents. Seven had $3+$ or 4+ albuminuria, and 4 others showed 1+ albuminuria. Gross or microscopic hematuria was noted in 4 instances.

Conditions which may have contributed to renal failure were observed during hospitalization in all but the 2 youngest subjects (clinical diagnosis, glomerulonephritis). Eight persons with renal failure were recorded as having congestive heart failure; in 6 it had been detected in the time of the initial examination.

Twelve of the 14 patients with renal failure died either during the index admission or within three months. Three deaths occurred within four weeks from myocardial infarction, and 3 others occurred within four weeks from cerebral thrombosis, hemorrhage, or embolism. Postmortem examinations in 3 cases revealed acute and subacute glomerulonephritis with terminal congestive failure (Case A); glomerulosclerosis, advanced coronary artery disease with old and new myocardial infarctions, pulmonary edema, and acute cystitis (Case B); and cerebral thrombosis with nephrosclerosis (Case L).

\section{DISCUSSION}

The methodology used in the present study was epidemiologic; a large population was initially surveyed and the incidence of renal failure followed over an eight-year period. The questionnaire technique was used to determine a history of urinary-tract infection (UTI). Although urine cultures would have been preferable as a basis for making this determination, the large number of subjects examined under "field conditions" created practical difficulties for culture collections which could not be overcome. In addition, urine cultures may have proved sterile in subjects with a past history of UTI who may have had subclinical active pyelonephritis.

It should be emphasized that the end-point in the study was renal failure (both primary and secondary defined on the basis of clinical, biochemical, and autopsy data), and not specified pathologic entities (i.e., chronic pyelonephritis or glomerulonephritis). Although the cases were pathologically heterogeneous, grouping them together was justified on the basis that renal failure developed in all. Therefore, it is reasonable to search for common factors among initial findings which might have contributed to the development of renal disease and failure.

It is possible that some cases of renal failure were missed because of population mobility, mistaken diagnoses, and admissions to hospitals other than Herrick Memorial (the only hospital in Tecumseh, Michigan). However, analysis of the general pattern of medical care in Tecumseh indicates that most patients are admitted to Herrick Memorial. In addition, all death certifi-

TABLE 5

Observed and Expected Frequencies in Subsequently Uremic Subjects in Highest Age-and-Sex Specific Quintiles of Selected Physiologic Variables at Initial Examination (Tecumseh, Mich., 1959-1960)

\begin{tabular}{lcc}
\hline \multicolumn{1}{c}{ Variable } & Observed & Expected \\
\hline Systolic blood pressure & 4 & 3.2 \\
Diastolic blood pressure & 2 & 3.2 \\
Serum cholesterol & 4 & 3.2 \\
Blood glucose* & 5 & 3.7 \\
Serum uric acid & 5 & 2.8 \\
\hline
\end{tabular}

* Highest quintile of blood glucose specific for age, sex and test conditions. Expected number includes previously known diabetic patients.

TABLE 4

Frequency of a Prior History Compatible with a Urinary-Tract Infection (UTI), at Initial Examination in Persons 45 Years of Age and Over With or Without Subsequent Renal Failure (Tecumseh, Mich., 1959-1967)

\begin{tabular}{|c|c|c|c|c|}
\hline & $\begin{array}{c}\text { UTI } \\
\text { History }\end{array}$ & $\begin{array}{l}\text { No UTI } \\
\text { History }\end{array}$ & $\begin{array}{c}\% \\
\text { with UTI }\end{array}$ & Total \\
\hline $\begin{array}{l}\text { Renal failure } \\
\text { No renal failure }\end{array}$ & $\begin{array}{r}6 \\
380\end{array}$ & $\begin{array}{r}6 \\
1,366\end{array}$ & $\begin{array}{l}50 \% \\
22 \%\end{array}$ & $\begin{array}{r}12 \\
1,746\end{array}$ \\
\hline $\begin{array}{l}\text { Per cent of subjects } \\
\text { with or without UTI* } \\
\text { history, in whom } \\
\text { renal failure developed }\end{array}$ & $1.6 \%$ & $0.4 \%$ & & \\
\hline
\end{tabular}

* Urinary Tract Infection 
cates on participants were followed up whether the participants had moved or not.

Unlike the intensive clinical and pathologic study of renal disease mortality in Goteberg, Sweden, the specific renal pathologic lesion was known in few of the present cases (13). Nevertheless, the requirement that either the SUN had to exceed $75 \mathrm{mg} / 100 \mathrm{ml}$ or that autopsy findings supporting the clinical impression of "renal death" had to be present in each case, served to insure that the 14 subjects of this study probably had underlying renal disease when renal failure became evident. Urinary abnormalities generally present at that time also support this view.

Information on possible precursors to renal failure has not previously been reported from longitudinal epidemiologic studies such as Framingham or Tecumseh. Part of the reason for this paucity of data is the low rate at which renal failure develops among subjects in a given study population. Among the 8,641 participants of all ages at the time of the initial examination in this community study, in only 14 (0.2 per cent) did renal failure develop during an eight-year period. The 12 who died while in a state of renal failure yield an annual mortality rate of 172 per million. This is higher than rates reported from recent statistical studies of mortality ascribed to renal diseases in the United States, England and Wales, Switzerland, and Israel but comparable to that reported from Denmark (14-18). In Britain (for 1967), diseases likely to result in uremia caused 1.4 percent of all deaths (137 deaths per million) (30). Most of the deaths due to such causes were in persons over age $50-a$ finding similar to that observed in the present study. Lower incidences of uremia and deaths due to renal failure in certain studies can be explained by the exclusion of patients over 50 years of age from analysis and by the classification of fatalities due to cardiovascular diseases which culminated in uremia under categories other than renal failure or uremia.

Recently Pendreigh et al. (30) McGeown (31) and Branch et al. (32) studied the prevalence of renal failure and requirements for maintenance dialysis in Wales, Northern Ireland, and Scotland respectively (the definition of renal failure was a blood urea level over 100 $\mathrm{mg} / \mathrm{ml}$ ). Their findings were similar to ours in that the majority of patients experiencing renal failure were over age 50 . The rate of new patients requiring hemodialysis was 39 per million per year under age 60 and 28 per million per year under age 50 in the Welsh study, 38 per million per year under age 60 in the Irish study, and 52 per million per year under age 65 in the Scottish study. The rate of participants possibly requiring dialysis in Tecumseh was 29 per million per year under age 45.

In the present study, renal failure increased significantly with age. This finding had previously been documented by Pendreigh et al., McGeown, and Branch et al. (30-32). Branch and associates showed a striking preponderance of elderly patients; 92 per cent of those with renal failure were age 50 or older. In our study, 86.6 per cent of the renal-failure subjects were over 45 years of age.

In "normal" people, renal function falls progressively after 30 years of age $(33,34)$. This impairment of renal function is usually not clinically apparent, but when the stress of cardiac failure, shock, infection, or dehydration supervenes, such impairment may become significant. The high mortality due to, or complicated by, renal failure in the elderly has been noted previously $(35,36)$. It is not clear whether this gradual reduction of renal function with age is due to an increasing incidence of renal disease in the elderly or to "senile nephrosclerosis" (37, 38). In our study, all 12 of the uremic subjects over age 45 had a significant degree of cardiovascular disease contributing to renal failure.

Histories suggestive of urinary-tract infection (UTI) were obtained from 6 of the 12 renal-failure subjects over age 45 - somewhat in excess of the number expected by chance alone. Whether isolated UTI's are an important cause of renal failure is debatable $(5,10)$. Epidemiologic studies of bacteriuria have not demonstrated progression to chronic renal disease in otherwise healthy persons. Among Tecumseh residents examined in 1959 and 1960 , it is noteworthy that the great majority who gave histories of UTI did not subsequently manifest chronic renal disease. Our data, however, suggest a limited relationship of UTI to renal failure in a small proportion of persons over age 45 who have other predisposing diseases.

Several conditions were found commonly at initial examinations of the patients who subsequently became uremic. In accord with past 
experience, the prominence of congestive heart failure and coronary heart disease in these subjects may well be attributable to their effect in lowering renal blood flow. It is possible that heart disease and UTI may work together in other persons to cause lethal kidney damage (39). In our study, all 6 subjects with prior UTI who later manifested renal failure had coexistent heart disease at the time of the initial examinations.

The unexpected observation that half of those who later had renal failure also had loss of hearing was not explainable from available data; perhaps this could be ascribed in part to drugs which are potentially toxic to both the eighth nerve and the nephron (40). A hereditary association of nerve deafness and renal failure has also been shown (41). The initial examining physicians usually assumed that the observed deafness in these subjects was the result of presbycusis, a condition which is difficult to relate to subsequent renal failure. Certainly, the relationship between hearing loss and subsequent renal failure requires further study.

At the initial examination (one to seven years before renal failure), objective evidence (abnormal urinalysis findings; elevated level of serum creatinine or urea nitrogen) for the presence of renal disease or renal failure was found in 4 of 14 subjects. Hypertension was found in no more than the expected frequency despite its common association with renal disease and its occurrence terminally in 8 of the present 14 subjects (29).

Several factors known or suspected to increase the risk of coronary or other atherosclerotic disease were studied in the hope of identifying some which might contribute to renal failure. However, though at least one reason for the increased risk of atherosclerosis was found at the time of the initial examination in 10 of the 14 subjects, only hyperuricemia was found somewhat more often than expected by chance. In some subjects, elevated uric acid values could have been due to impaired renal function as suggested by moderate elevations of serum urea nitrogen or creatinine levels. It is possible that the lack of relationship between renal failure and risk factors for coronary disease may be due to the age of the renal-failure subjects. Risk factors for coronary disease lose specificity with advancing age.
The two youngest subjects, who died of glomerulonephritis (clinical diagnosis) with only minimal terminal evidence of congestive failure would have been the only candidates for renal transplantation or long-term dialysis. The other subjects with irreversible renal failure would have been precluded from consideration because of advanced age and/or extra-renal disorders. According to recent estimates for the U.S. population 15 to 54 years of age, the number of dialysis candidates from the 4,500 Tecumseh residents in this age range in the eight years since initial examinations would be roughly 2.2 , which is in agreement with our findings (10).

Because the number of persons in this population in whom renal failure developed within the period of study was small, it was not possible to establish the exact relationship between factors observed at the initial examinations and later renal failure. However, there is a suggested relationship between certain factors (pre-existing cardiovascular disease, history of urinary-tract infection, deafness) and eventual renal failure. The addition of considerably more person-years of experience from this and similar longitudinal studies is needed so that such relationships may be more clearly established. Continued investigation of precursors to renal failure is essential to the development of preventive programs, an important long-range goal.

\section{Acknowledgments}

The authors are indebted to Mrs. Nelson Meade and Messrs. Jacob Keller and John Napier of the Tecumseh Study staff and to Mrs. Max Steuwe, Medical Record Librarian and Mr. William Groover, Administrator, Herrick Hospital, for assistance in locating and assembling data reported here. Helpful criticism was provided by other members of the Tecumseh Study staff. We are grateful to Mrs. Carl Wendtland who typed the manuscript.

\section{REFERENCES}

1. Kass EH: Renal and urinary disorders, in Preventive Medicine, ed. by DW Clark and B MacMahon. Boston; Little, Brown and Co., 1967, pp. 539-552.

2. Kunin CM, Deutscher $R$ and Paquin A Jr: Urinary tract infection in school children: an epidemiologic, clinical and laboratory study, Medicine 43: $91,1964$.

3. Kunin CM and McCormack RC: An epidemiologic study of bacteriuria and blood pressure among nuns and working women, New England J Med 278: 635, 1968.

4. Kaitz AL: Urinary concentrating ability in preg- 
nant women with asymptomatic bacteriuria, J Clin Invest $40: 1331,1961$.

5. Kincaid-Smith $P$ and Bullen $M$ : Bacteriuria in pregnancy, Lancet 1:395, 1965.

6. Little PJ and De Wardener HE: Acute pyelonephritis: incidence of reinfection in 100 patients, Lancet $2: 1227,1966$.

7. Freedman LR: Chronic pyelonephritis at autopsy, Ann Int Med, 66: 697, 1967.

8. Fry J, Dillane JB, Joiner CL and Williams JD: Acute urinary infections: their course and outcome in general practice with special reference to chronic pyelonephritis, Lancet $1: 1318,1962$.

9. Angell ME, Relman AS and Robbins SL: "Active" chronic pyelonephritis without evidence of bacterial infection, New England J Med 278: 1303, 1968.

10. Gottschalk CW (Chmn.): Report of Committee on Chronic Kidney Disease. Washington, D.C., Gov* ernment Printing Office, Publ. No. 933-491, September, 1967. (197 pp.)

11. Jennings RB and Earle DP: Post-streptococcal glomerulonephritis: histopathologic and clinical studies of the acute, subsiding acute and early chronic latent phases, $J$ Clin Invest 40: 1525, 1961.

12. Perlman LV, Herdman RC, Kleinman $H$ and Vernier RL: Post-streptococcal glomerulonephritis: a ten year follow-up of an epidemic, JAMA 194: 63,1965 .

13. Hood B, Falkheden $T$ and Carlsson $M$ : Trends and present pattern of mortality in chronic uremia, Acta Med Scandinav. 181: 561, 1967.

14. Kessner DM and Florey C Du V: Mortality trends for acute and chronic nephritis and infections of the kidney, Lancet 2: 979, 1967.

15. Waters WE: Trends in mortality from nephritis and infections of the kidney in England and Wales, Lancet 1: 241, 1968.

16. Hamtoft $H$ and Mosbech $\mathrm{J}$ : Mortality trends in renal disease, Lancet 1: 751, 1968.

17. Dubach US: Motalitätsentwicklung für Nierenleiden in der Schweiz 1947-1966, Schweiz Med Wchnschr 98(40): 1542, 1968.

18. Modan B, Moore BP and Paz B: Mortality from renal disease in Israel-Some epidemiological aspects, J Chron Dis 22: 727, 1970.

19. Napier JA: Field methods and response rates in the Tecumseh Community Health Study, Am J Public Health 52: 208, 1962.

20. Epstein FH, Ostrander LD, Johnson BC et al: Epidemiological studies of cardiovascular disease in a total community-Tecumseh, Michigan, Ann Int Med 62: 1170, 1965.

21. Epstein FH, Francis $T$ Jr, Hayner NS et al: Prevalence of chronic diseases and distribution of selected physiological variables in a total community-Tecumseh, Michigan, Am J Epidemiology 81:307, 1965

22. Johnson BC, Epstein FH and Kjelsberg MO: Distributions and familial studies of blood pressure and serum cholesterol levels in a total community-Tecumseh, Michigan, J Chron Dis 18: 147, 1965.

23. Mikkelsen WM, Dodge $H J$ and Valkenburg $H$ : The distribution of serum uric acid levels in a population unselected for hyperuricemia or gout, Am J Med 39: 242, 1965.

24. Hayner NS, Waterhouse AM and Gordon T: The one-hour oral glucose tolerance test: response of middle-aged men to 100 -gram and 50 gram doses of glucose given fasting and 1,2, and 3 hours after meal. Washington, D.C.; U.S. Department of Health, Education, and Welfare, Public Health Service, National Center for Health Statistics (Vital Health Statistics, series 2, No. 3), 1963.

25. Hayner NS, Kjelsberg MO, Epstein FH et al: Carbohydrate tolerance and diabetes in a total community, Tecumseh, Michigan. I. Effects of age, sex, and test conditions on one-hour glucose tolerance in adults, Diabetes 14: 413, 1965.

26. Marsh WH, Fingerhut B and Kirsch E: Determination of urea nitrogen with the diacetyl method and an automatic dialyzing apparatus, Am J Clin Path 28: $681,1957$.

27. Folin $\mathrm{O}$ and WU $\mathrm{H}$ : A system of blood analysis, $\mathrm{J}$ Biol Chem 38: 81, 1919.

28. Tecumseh Community Health Study. Unpublished data, 1961.

29. Vertes V, Cangiano JL, Berman LB et al: Hypertension in end-stage renal disease, New England $J$ Med 280: 978, 1969.

30. Pendreigh DM, Howitt LF, Macdougall Al et al: Survey of chronic renal failure in Scotland, Lancet 1: 304, 1972.

31. McGeown MG: Chronic renal failure in Northern Ireland, 1968-1970. A prospective study, Lancet 1: 307, 1972.

32. Branch RA, Clark CW, Cochrane AL et al: Incidence of uremia and requirements for maintenance hemodialysis, Brit Med J 1: 249, 1971.

33. Lewis WH and Alving AS: Changes with age in renal function in adult men; clearance of urea; amount of urea nitrogen in blood; concentrating ability of kidneys, Am J Physiol 123: 500, 1938.

34. Davies DF and Shock NW: Age changes in glomerular filtration rate, effective renal plasma flow, and tubular excretory capacity in adult males, J Clin Invest 29: 496, 1950.

35. Agate J: The Practice of Geriatrics (2nd ed.). London, Heinemann, 1970.

36. Heider $\mathrm{CH}$ and Brest $\mathrm{AN}$ : Renal insufficiency in the aged, Geriatrics 18: 489, 1963.

37. Lapides $J$ and Zierdt $D$ : Compatibility of normal renal function with aging, JAMA 201: 788, 1967.

38. Oliver JR: In Cowdry's Problems of Aging ed. by A Lansing (3rd ed.) Baltimore, Williams and Wilkins, 1952.

39. Curtis JR: Urinary tract infection in the elderly woman, J Gerontol 22: 502, 1967.

40. Bernheim F: Drugs used in the treatment of tuberculosis, in Drill's Pharmacology in Medicine, ed. by JR DiPalma (3rd ed.). New York, McGraw Hill Book Co., 1965, pp. 1337-1348.

41. Perkoff GT, Nugent CA Jr, Dolowitz DA et al: Follow-up study of hereditary chronic nephritis, AMA Arch Int Med 102: 733, 1958.

42. Wyngaarden JB: Etiology and pathogenesis of gout, in Arthritis and Allied Conditions: A Textbook of Rheumatology, ed. by JL Hollander (7th ed.). Philadelphia, Lea and Febiger, 1966, pp. 899-922. 